\title{
Effect of the addition of soybean dregs treated by ultrafine grinding and microwave technology on the quality of crispy biscuits
}

Fang Wang ${ }^{1,2}$, Valerii Sukmanov ${ }^{1,3}$, Jie Zeng ${ }^{2}$

\author{
1 - Sumy National Agrarian University, Sumy, Ukraine \\ 2 - Henan Institute of Science and Technology, Xinxiang, People's Republic of China \\ 3 - Poltava State Agrarian University, Poltava, Ukraine
}

\begin{tabular}{|c|c|}
\hline & Abstract \\
\hline Keywords: & $\begin{array}{l}\text { Introduction. The aim of the research is to determine the effect } \\
\text { of the addition of soybean dregs treated with ultrafine grinding and }\end{array}$ \\
\hline Soybean & microwave irradiation on the quality of crispy pastry. \\
\hline Dregs & Materials and methods. The moist soybean dregs were dried at \\
\hline Crispy biscuits & $50^{\circ} \mathrm{C}$ for 48 hours and ground in an ultrafine grinding machine $\mathrm{KCW}-$ \\
\hline Ultrafine & $701 \mathrm{~S}$ at a frequency of $30 \mathrm{~Hz}$. Obtained soybean flour was processed \\
\hline Grinding & in a microwave oven, the ratio of beans to water was set to $1: 7$, at a \\
\hline Microwave & $\begin{array}{l}\text { high level of heating for } 6 \mathrm{~min} \text {, then dried in an oven at } 50{ }^{\circ} \mathrm{C} \text { for } 48 \\
\mathrm{~h} \text { and sieved at } 80 \mathrm{mesh} \text {. The color }\left(L^{*}, a^{*}, b^{*}\right) \text { values of the crackers }\end{array}$ \\
\hline & $\begin{array}{l}\text { were determined by portable color difference meter (Cr- } 400 \\
\text { chromatic aberration meter Minolta, Japan).was determined using }\end{array}$ \\
\hline Article history: & $\begin{array}{l}\text { chromatic aberration meter Cr- } 400 \text {; texture was determined by the } \\
\text { TA-XT Plus Texture Analyzer; sensory evaluation was conducted by }\end{array}$ \\
\hline $\begin{array}{l}\text { Received } \\
30.03 .2021\end{array}$ & $\begin{array}{l}\text { 100-point hedonic scale for color, flavor, texture and overall } \\
\text { acceptability. }\end{array}$ \\
\hline
\end{tabular}

Received in

revised form

28.08.2021

Accepted

30.12 .2021

Results and discussion. The increase of the amount of soybean dregs powder (SDP) decreased $L^{*}$ and increased $a^{*}$ values of crispy biscuits, meanwhile $b^{*}$ values were not changed significantly. The color of crispy biscuits became darker (lower $L^{*}$ ), more reddish (higher $a^{*}$ ), and less yellowish (lower $b^{*}$ ) when soybean dreg powder was added at amount of 15-25\%. The hardness of crispy biscuits increased gradually with the increase of bean dregs. The hardness reached the maximum of $2328.49 \mathrm{~N}$ at addition of SDP $15 \%$. With the addition of SDP at $20 \%$, the firmness of the biscuits decreased slightly. With increasing addition of SDP, the content of dietary fiber in the crispy biscuit increased, thereby reducing the gluten content in the dough and affecting the formation of the gluten network, which led to an increase in the hardness of the crispy biscuit. Increasing of the dietary fiber content ensures retaining of oil in the crispy biscuits, which results in a reduction of the product hardness. The addition of soybean dregs powder affected the sensorial properties of the product. However, there was no significant difference in the overall quality rating of the crispy biscuits containing 15 and 20\% SDP.

Conclusion. The addition of bean dreg powder had significant effects on the color, texture and sensorial properties of crispy biscuits

DOI:

$10.24263 / 2304-$ 974X-2021-10-44 compared with control. However, crispy biscuits with the addition of soybean dregs powder in the amount of 15-20\% prepared by proposed technology had the crispy taste, golden color, and pleasant soybean flavor. 


\section{Introduction}

By-products of plant processing are widely used in food preparation (Stabnikova et al., 2021). The soybean dregs is residue from soy milk production containing insoluble components, which remain in the filtration bag (O'Toole \& Desmond, 1999). Dry soybean dregs has high content of proteins (24.5-37.5 g/100 g), lipids (9.3-22.3 g/100 g), dietary fiber $(14.5-55.4 \mathrm{~g} / 100 \mathrm{~g})$, and is a good source of isoflavones (Bourquin et el., 1996; Rinaldi et al., 2000; Tharanathan \& Mahadevamma, 2003; Surel \& Couplet, 2005; Pr'estamo et al., 2007; Redondo-Cuenca et al., 2008).

With the development of the soy milk production, the availability of soybean dregs has been gradually increased, and now they are commonly used in the manufacturing of baked goods such as cakes, bread, and biscuits (Yang et al., 2013). Addition the soybean dregs into flour not only improved the flavor of the traditional biscuits, but also provided a new type of healthy food for consumers (Chen, 2013; Yang et al., 2013). However, soybean dregs have poor taste, perishability, and low content of soluble dietary fiber (SDF). Therefore, most of them are used as feed for animals or discarded as waste disposal. In recent years, a large number of studies have been carried out to develop physical technologies to increase the content of water-soluble fibers in bean flour, for example, explosive extrusion has increased the content of SDF in bean flour from 1.34 to $36.28 \%$ at an explosive strength of $1.5 \mathrm{MPa}$ within $30 \mathrm{~s}$ (Chen et al., 2014). Twin-screw extrusion was applied for soluble dietary fiber extraction from soybean residue. The SDF content of soybean dregs reached $12.65 \%$, which was by $10.60 \%$ higher than that of unextruded and boiled soybean dregs (Yan \& Chi, 2013). Steam explosion is a kind of physical method recently used in food pretreatment. When the explosion strength was $1.5 \mathrm{MPa}$ for $30 \mathrm{~s}$, the content of soluble dietary fiber of soybean dregs increased from 1.34 to $36.28 \%$ (Li et al., 2019). The solubility of bean dregs can be also increased using the high-pressure homogenization due to structural disruption of bean particles and release of fibre and proteins (Fayaz et al., 2019).

The dissolution rate of soluble polysaccharides in bean residue increased to $70 \%$ after microwave treatment at $200^{\circ} \mathrm{C}$ for $7 \mathrm{~min}$, while the appearance of new polyphenolic compounds with antioxidant activity was observed at temperatures above $180^{\circ} \mathrm{C}$ (Tsubaki et al., 2009). The content of soluble dietary fiber in soybean dregs increased 8 times during the treatment with high hydrostatic pressure of $400 \mathrm{MPa}$ at $60^{\circ} \mathrm{C}$. While there was also an improvement in swelling, water holding capacity and oil holding capacity of soybean dregs (Mateos-Aparicio et al., 2010). However, as far as we know, the treatment of bean dregs by physical techniques has not been used in preparation of baked products, and this topic requires further research.

In our previous research, the SDF contents in bean dregs treated with the above single and combination methods were determined according to the AOAC method (1995). The SDF contents in bean dregs after the ultrafine grinding (U), high pressure (HP), microwaves (M), high-temperature cooking (HTC) and combination technologies U-HP, U-M, U-HTC were $15.15 \pm 0.12 \%, 10.40 \pm 0.19 \%, 13.84 \pm 0.13 \%, 13.87 \pm 0.13 \%, 18.86 \pm 0.11 \%, 19.23 \pm 0.19 \%$, and $16.89 \pm 0.13 \%$, respectively. Meanwhile, the SDF content in the control sample was only $1.63 \pm 0.2 \%$ (Wang et al., 2021).

Therefore, the aim of the present research is to determine the effect of the addition of soybean dregs treated with ultrafine grinding and microwave irradiation on the quality of crispy biscuits. It can improve the dietary fiber intake and flavor as well as nutritional value of the crispy biscuits. 


\section{Materials and methods}

\section{Materials}

Wet soybean dregs were obtained at local markets (Fresh okra has high moisture content, bad taste and mouth feel, and is difficult to store).

Bean dregs powder, low-gluten flour, powdered sugar, butter, corn starch, egg yolks, salt, and baking powder were collected from local markets.

\section{Equipment}

Ultrafine grinder (KCW-701S, Beijing Yujie Yucheng Machinery Equipment Co., Ltd., Beijing, China); Microwave oven (P70D20N1P-G5, Guangdong Galanz Microwave Life Electric Appliance Manufacturing Co., Ltd., Zhongshan, China); Oven (YXD-60C, Guangzhou Saisida Machinery Equipment Co., Ltd., Baiyun Branch, Guangzhou, China.

\section{Methods}

\section{Combination technology}

Ultrafine grinding (U): the wet soybean dregs were dried in a constant temperature drying oven at $50{ }^{\circ} \mathrm{C}$ for $48 \mathrm{~h}$, and then ultrafine ground frequency of $30 \mathrm{~Hz}$ by an ultrafine grinder (KCW-701S).

Microwave (M): wet bean dregs were treated in a P70D20N1P-G5 microwave oven at a medium heat level for $4 \mathrm{~min}$, then dried in the oven at $50{ }^{\circ} \mathrm{C}$ for $48 \mathrm{~h}$ and sieved at 80 mesh.

Combination technology: the soybean dregs treated by ultrafine grinding were used as the raw material for combination with high pressure treatment, microwave treatment and high temperature cooking treatment. The ratio of soybean dregs to water was set as 1:3, 1:5, 1:7, 1:9 and 1:11. The other conditions were designed as follows: Ultrafine Grinding-Microwave (U-M): Low, M-Low (between low and medium heat), Med, M. High (between medium and high heat), High heat modes were selected for microwave conditions, and the treatment time ranged from 2 min to $10 \mathrm{~min}$.

The treatment of SDP was conducted according to the methods described in (Wang et al., 2021).

\section{Crispy dough preparation}

The crispy biscuits had the following formulation: low gluten flour and soybean dregs powder (100 g), butter (50 g), powdered sugar $(20 \mathrm{~g})$, corn starch $(5 \mathrm{~g})$, egg yolks $(20 \mathrm{~g})$, salt $(1 \mathrm{~g})$, and baking powder $(0.75 \mathrm{~g})$. Whisk butter until creamy and pale after the butter is softened, powdered sugar, salt and egg yolks were mixed for $1 \mathrm{~min}$ at speed 4 using a KitchenAid Professional mixer KPM5 (St. Joseph, Michigan, USA) to make it smooth, add the flour mixture (low gluten flour, bean dregs powder, corn starch and baking powder) in batches to make a soft dough. Seal with plastic wrap and leave at room temperature for 10 min. 


\section{Crispy biscuits preparation}

Preheat the oven to be preheated, the upper heat is $170{ }^{\circ} \mathrm{C}$, the lower heat is $160{ }^{\circ} \mathrm{C}$, weigh $8 \mathrm{~g}$ of the crispy dough, put it into a fixed mold, press it into a consistent biscuit shape and slowly the sample into the prepared baking pan. These samples were baked in an electric oven for 12 minutes. After baking, the crispy biscuits were removed from the oven, left to cool for 1 hour at room temperature, and packed into hermetically sealed plastic bags to prevent drying. All quality measurements were performed in 1 hour after baking.

\section{Crispy biscuits measurements}

\section{Color}

The color $\left(L^{*}, a^{*}, b^{*}\right)$ values of the crackers were determined by portable color difference meter (Cr-400 chromatic aberration meter Minolta, Japan). Color measurements were made of crust. All measurements were conducted at least three times. The $L^{*}$ value is a measure of lightness, ranging from black (0) to white (100), the $a^{*}$ value ranges from greenness $(-100)$ to redness $(+100)$, and the $b^{*}$ value ranges from blueness $(-100)$ to yellowness (100) (Yang et el., 2019).

\section{Texture analysis}

Crispy biscuits texture was determined by the TA-XT Plus Texture Analyzer (Stable Micro Systems, London, UK) according to the method described in (Tyagi et al., 2007). The complete biscuits were placed on the test bench of the texture tester, and the texture profile analysis test was carried out with the $\mathrm{P} / 5$ probe. Parameters were set as follows: pretest peed, $1.0 \mathrm{~mm} / \mathrm{s}$; test speed, $0.50 \mathrm{~mm} / \mathrm{s}$; posttest speed, $1.0 \mathrm{~mm} / \mathrm{s}$; strain, $30 \%$; interval time, $5 \mathrm{~s}$. Textural parameters, such as hardness, cohesiveness, gumminess and chewiness were determined. Measurements were performed on biscuits ( $5 \mathrm{~mm}$ thick), and the mean of the four measurements was recorded.

Samples were assessed for texture profile analysis with an aluminum cylindrical probe $\mathrm{P} / 5$ at ambient temperature $\left(20-25^{\circ} \mathrm{C}\right)$. The indicators of hardness, springiness, cohesiveness and chewiness were determined. Each measurement was replicated 5 times.

The data were generated by Exponent software (Exponent stable microsystem, version 5.1.2.0, Stable Microsystems Ltd., UK) provided with the instrument (Figure 1). Attributes of hardness, cohesiveness, gumminess and chewiness were determined. Each measurement was replicated 5 times.

Hardness. It is the biggest peak of compression for the first time (Bourne, 2002; Singh et al., 1993).

Cohesiveness. The relative resistance of the test sample to the second compression after the first compression deformation is shown in the curve as the ratio of positive work (Area 2 /Area 1) of the two compressions. This value represents the total work required to overcome the attraction between the two surfaces when the probe comes into contact with the sample [27].

Gumminess. It is expressed as the product of hardness and cohesiveness. The result is multiplied by 100 to eliminate decimals (Friedman et al., 1963).

Chewiness. It is only used to describe the test sample in solid state, indicating the energy required to chew the solid sample into a stable state when swallowing. The numerical value is expressed by the product of the stickiness and elasticity (hardness $\mathrm{x}$ cohesive elasticity) 
[27].

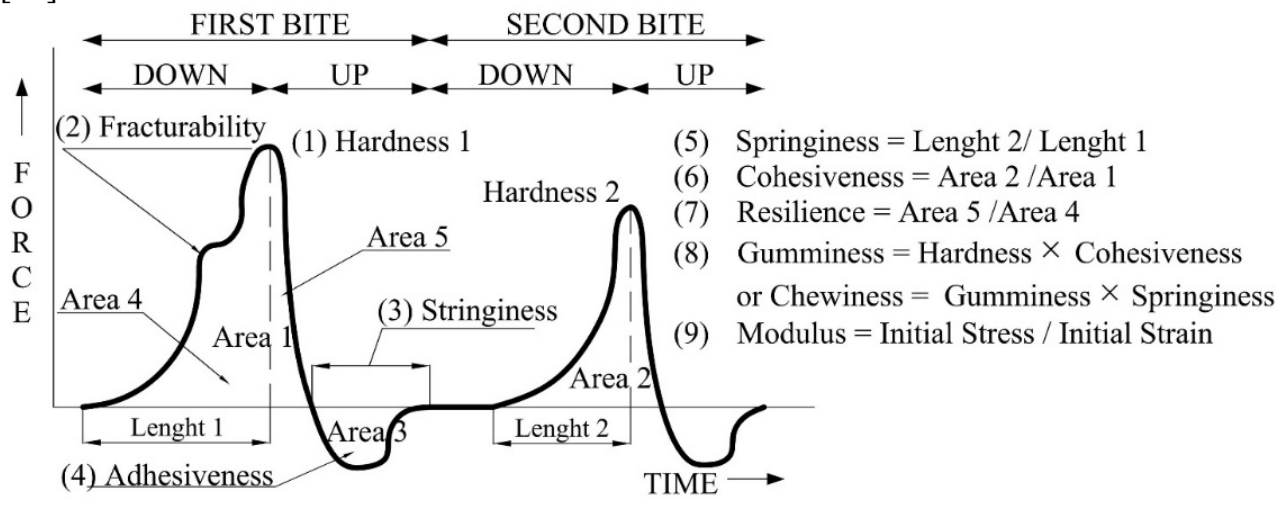

Figure 1. The parameter definition interpretation of qualitative curve analytical method (Szczesniak, 1963; Szczesniak et al., 1963)

\section{Sensory evaluation}

The sensory evaluation was done according to the method (Bose \& Shams-ud-Din, 2010). A sensory evaluation of biscuits was conducted initially for color, flavor and texture by a panel of 10 panelists (Qiu \& Qi, 2018). All the panelists were the postgraduate students of the Department of Food Science and Technology. A 100-point hedonic rating test was performed to assess the degree of acceptability of these biscuits. Three pieces from each biscuit lot were presented to 10 panelists as randomly coded samples. The test panelists were asked to rate the sample on a 100-point hedonic scale for color, flavor, texture and overall acceptability.

\section{Statistical analysis}

Experiments were conducted at least in triplicate, and the data were statistically analyzed and expressed as the means \pm standard deviation (SD). Data were subjected to analysis of variance (ANOVA) using the software package SPSS 12.0 for Windows (SPSS Inc., Chicago, USA) and $p<0.05$ was used as the standard for significance.

\section{Results and discussion}

\section{Analysis of color of crispy biscuits from bean dregs}

In Figure 2 shows examples of crispy biscuits produced with different amount of bean dregs and Table 2 presents the results of experiments evaluating the effect of using waste bean powder on crisp color. 


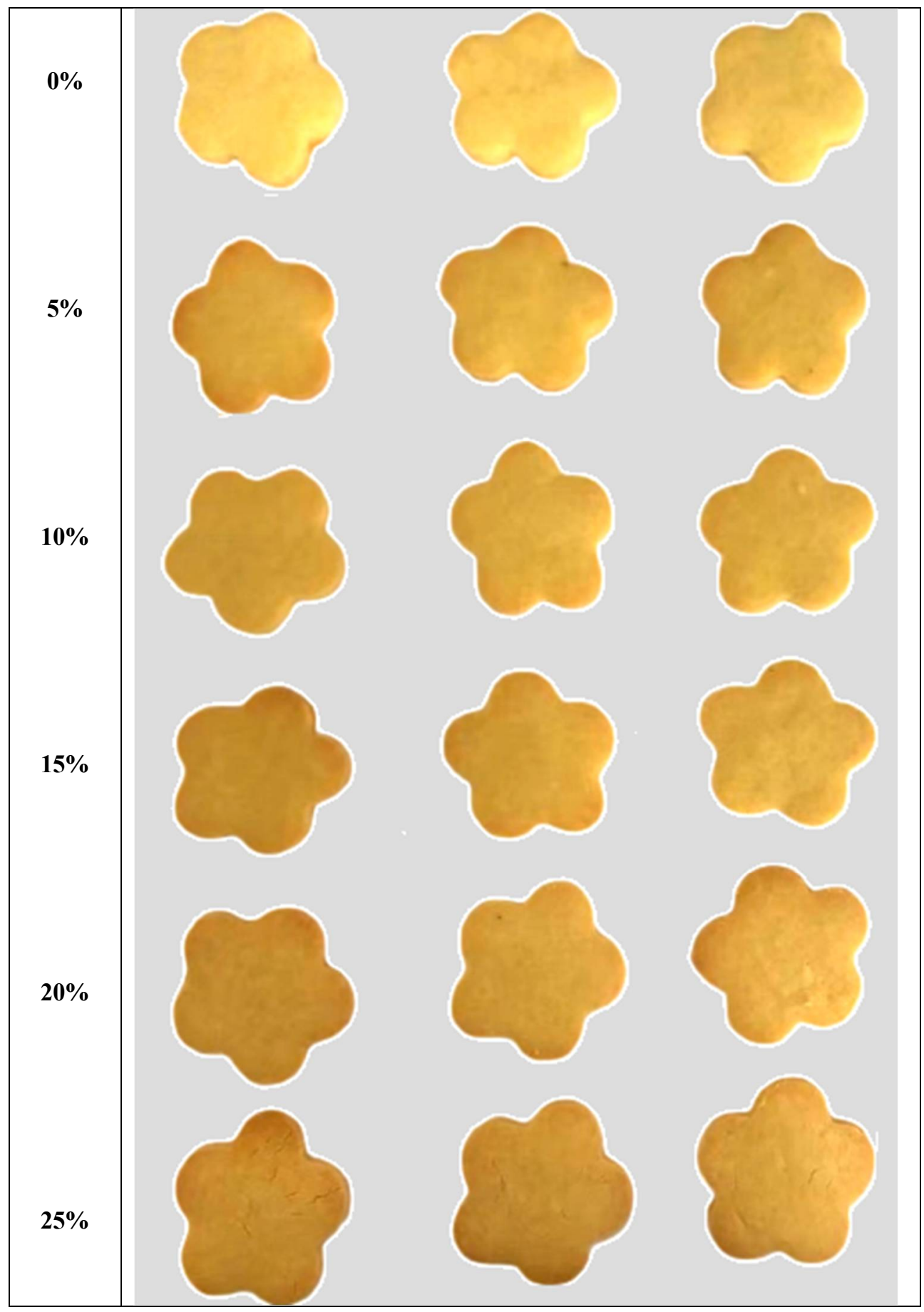

Figure 2. Morphology of crispy biscuits with different amount of soybean dregs powder 
Effect of soybean dregs powder on color of crispy biscuits

\begin{tabular}{|c|c|c|c|}
\hline $\begin{array}{c}\text { Soybean dregs } \\
\text { powder, \% }\end{array}$ & $\boldsymbol{L}^{*}$ & $\boldsymbol{a}^{*}$ & $\boldsymbol{b}^{*}$ \\
\hline 0 & $75.59 \pm 0.74^{\mathrm{a}}$ & $-1.00 \pm 0.10^{\mathrm{f}}$ & $34.14 \pm 0.26^{\mathrm{c}}$ \\
\hline 5 & $74.31 \pm 0.26^{\mathrm{a}}$ & $1.01 \pm 0.07^{\mathrm{e}}$ & $36.17 \pm 0.13^{\mathrm{a}}$ \\
\hline 10 & $72.30 \pm 1.06^{\mathrm{b}}$ & $1.78 \pm 0.19^{\mathrm{d}}$ & $34.67 \pm 0.44 \mathrm{~b}^{\mathrm{c}}$ \\
\hline 15 & $70.59 \pm 1.11^{\mathrm{c}}$ & $2.93 \pm 0.38^{\mathrm{c}}$ & $34.86 \pm 0.34^{\mathrm{b}}$ \\
\hline 20 & $70.57 \pm 0.30^{\mathrm{c}}$ & $3.83 \pm 0.14^{\mathrm{b}}$ & $34.14 \pm 0.22^{\mathrm{c}}$ \\
\hline 25 & $69.70 \pm 0.69^{\mathrm{c}}$ & $4.17 \pm 0.06^{\mathrm{a}}$ & $34.28 \pm 0.33^{\mathrm{c}}$ \\
\hline
\end{tabular}

Data reported as mean \pm standard deviation, $n=3$. Values followed by different lower-case letters in the same column are significantly different from each other $(\mathrm{p} \leq 0.05)$.

The increase of the amount of SDP decreased $\mathrm{L}^{*}$ and increased a* values for crispy biscuits, indicating more dark and yellowish color, meanwhile $\mathrm{b}^{*}$ values were not changed significantly. The crisp biscuits color became darker (lower L*), more reddish (higher a* values), and less yellowish (lower $\mathrm{b}^{*}$ ) when soybean dregs powder was added at the amount of $15-25 \%$. The crust of the crispy biscuits was caramelized during baking and was responsible for the final color of the crust. The Mallard reaction involves a complex sequence of reactions, including condensation, cyclization, dehydration, rearrangement, isomerization, and polymerization. Thus, these changes in the color parameters may be related to the Mallard reaction, which is a temperature-dependent nonenzymatic reaction between reducing sugars and the amino groups of amino acids or proteins, resulting in the formation of brown pigments (melanoidins) (Muliterno et al., 2017).

\section{Analysis of texture of crisp biscuits from bean dregs}

The results of experimental studies of the effect of bean dregs powder on texture of crisp biscuits are shown in Figure 3. 

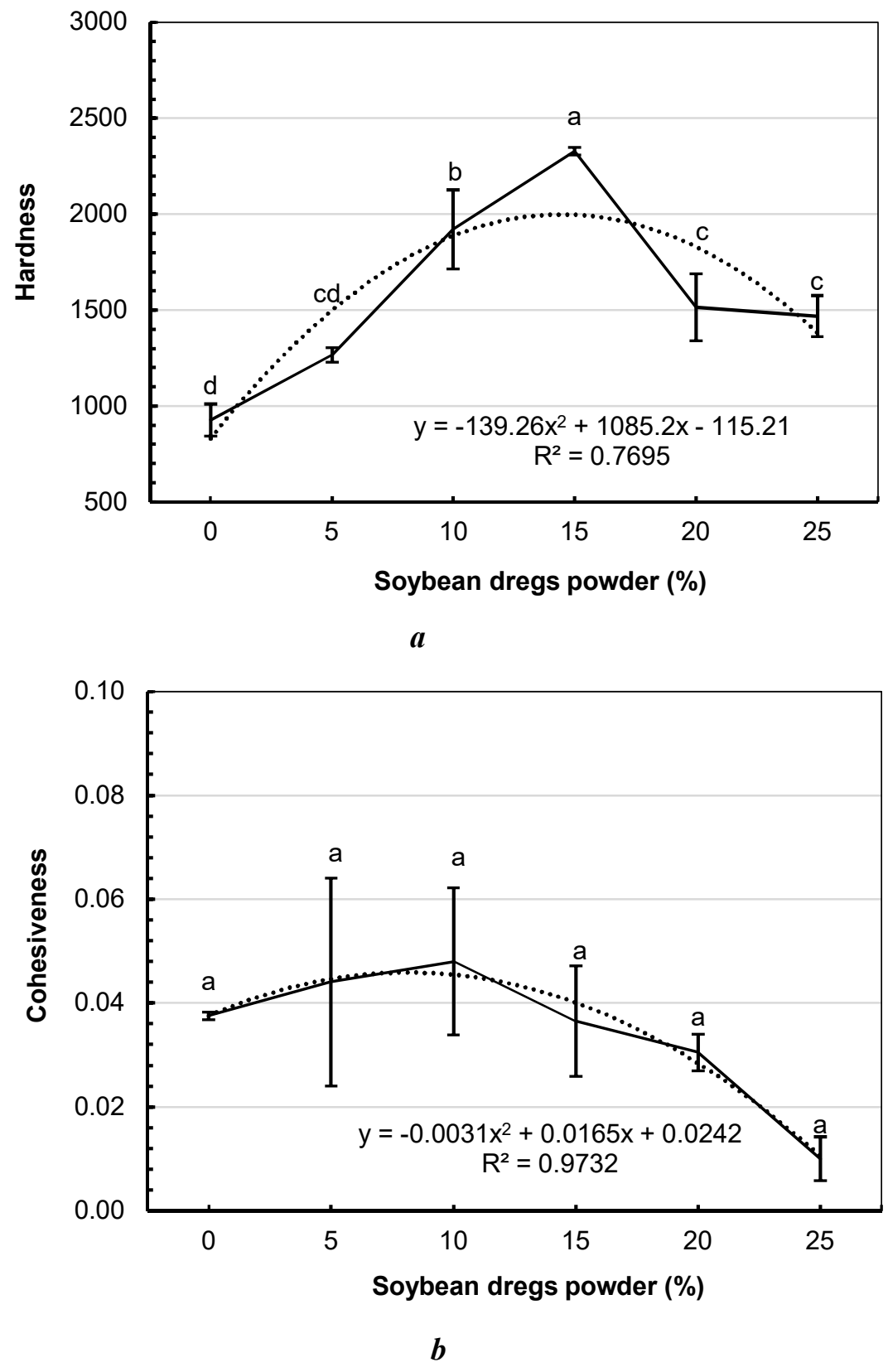

Ukrainian Food Journal. 2021. Volume 10. Issue 4 - 685 


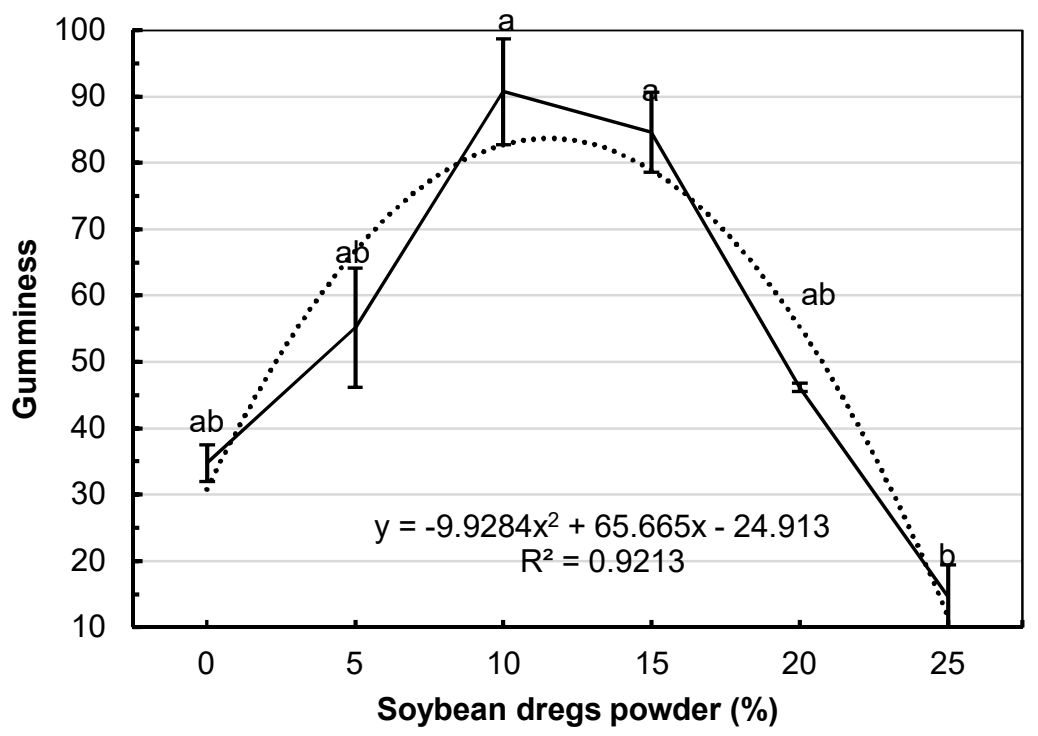

$\boldsymbol{c}$

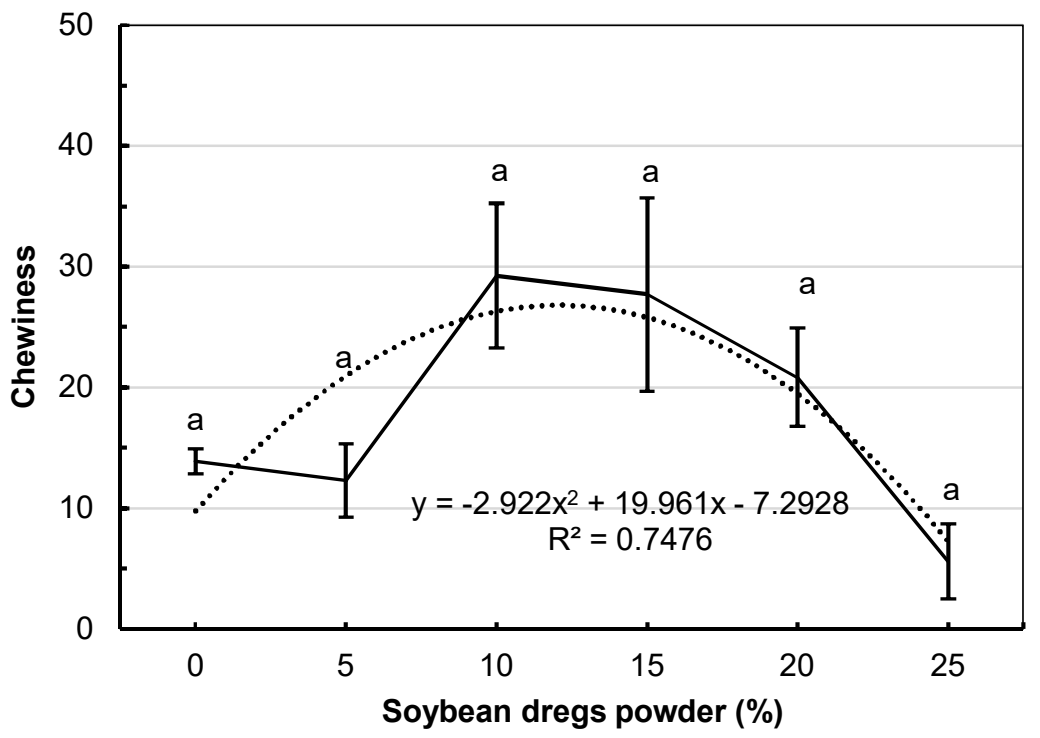

$d$

Figure 3. Effect of bean dregs powder on texture of crisp biscuits: a - hardness; $b$ - cohesiveness; $c$ - gumminess; $d$ - chewiness.

Data reported as mean \pm standard deviation, $n=3$. Values followed by different lower-case letters in the same column are significantly different from each other $(\mathrm{p} \leq 0.05)$. 
Biscuit texture is an important index to evaluate the biscuits quality, lower in hardness and chewiness of biscuit indicated less work to be consumed when chewing (Yang et al., 2019). However, biscuits with a certain hardness require more saliva when chewing, taste better and aging rate can be delayed. The effect of different contents of soybean dregs powder on biscuit texture are presented in Figure 3 (a-d). Hardness of the crispy biscuits with SDP was significantly higher than of control $(\mathrm{p}<0.05)$. When the soybean dregs powder was added at the amount of $15 \%$, the hardness reached the maximum of $2328.49 \mathrm{~N}$. This may be due to increase of the content of fiber that capable to absorb water or oil in dough, fills in the gluten network and leads to the increase of dough hardness (Yang et al., 2019). The hardness decreased and biscuits became very dark with bean flavor when the amount of soybean dregs powder was above $20 \%$. At the content of SDP $10-20 \%$, gumminess and chewiness of the biscuit increased and became higher than of control. Similar results were reported at the evaluation of addition of banana powder on biscuit texture (Li et al., 2015). SDP content showed great correlation with the cohesiveness and gumminess properties of crispy biscuits. The value of $\mathrm{R}^{2}$ was close to 1 , indicating that the regression line fits the observed value well (b, c). In addition, the index between biscuit hardness and soybean dregs powder content was 0.770 (a), and the index between biscuit chewiness and the content of SDP was 0.748 (d), showing that soybean dregs powder had different effects on cohesiveness and chewiness of crispy biscuits.

\section{Subjective (sensory) evaluation of crispy biscuits}

A comprehensive assessment of crispy biscuits with SDP is shown in Figure 4.

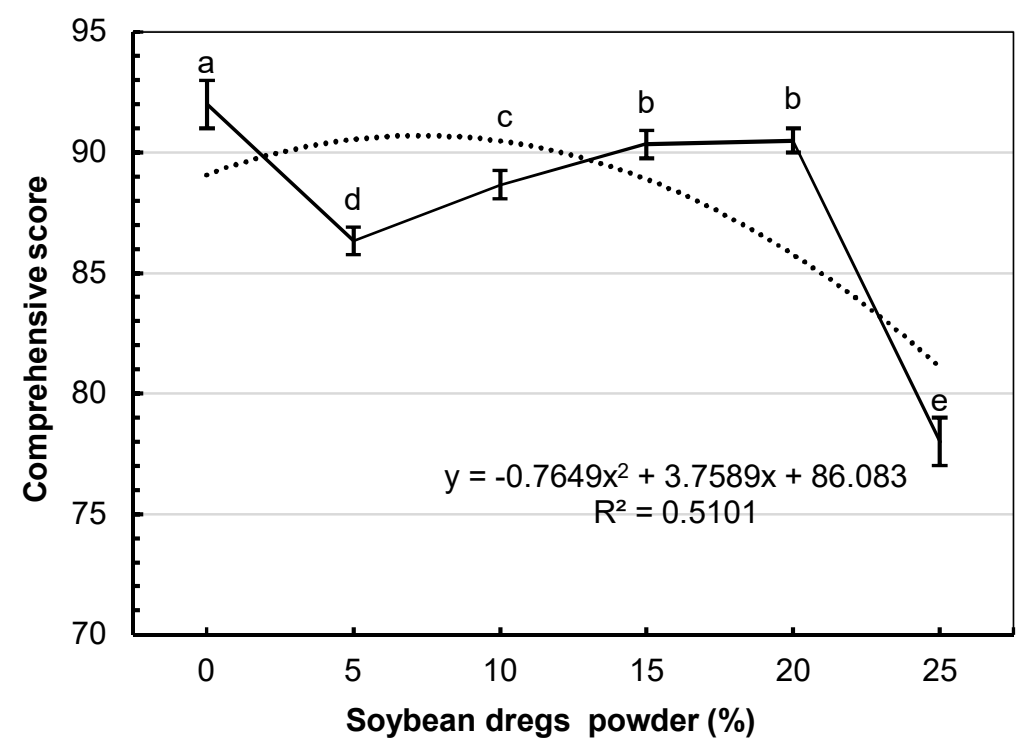

Figure 4. The comprehensive score of crispy biscuits with soybean dregs powder

In every group of data, values with the same following letter do not differ significantly from each other $(\mathrm{p} \leq 0.05)$. 
The mean scores for overall acceptability of biscuits were presented in Figure 4. A twoway analysis of variance indicated that these sensory attributes of the crispy biscuits were significantly affected $(p<0.05)$ by addition of different amounts of SDP in biscuit formulations. As shown in Figure 4, overall acceptability of the control crispy biscuits was the highest and it was significantly better than of the biscuits added with SDP. Biscuits containing soybean dregs powder (even up to $20 \%$ level of substitution) had superior scores, overall acceptability of biscuits were judged to be very good. Biscuits with higher amount of soybean dregs powder $(25 \%)$ had the typical bean flavor, and the scores of biscuits were affected adversely. Similarly, the color of biscuits became darker gradually with increasing levels of soybean dregs powder. Therefore, among the processed crispy biscuits, $15 \%$ and $20 \%$ of soybean dregs powder containing biscuit was the most preferred one than the biscuit containing $5 \%, 10 \%$ and $25 \%$ SDP. The results of sensory evaluation indicated that it is possiblu to use wheat flour with up to $20 \%$ substitution level with SDP without adversely affecting the consumer acceptability of biscuits. Similar results were obtained when evaluating the effect of composite flours prepared from wheat, greengram, bengalgram and blackgram flours on the sensorial characteristics of cookies (Singh et al., 1993).

\section{Conclusions}

1. The present work investigated the effects of addition of soybean dregs powder on characteristics of crispy biscuits. Color, texture and sensorial characteristics were determined to evaluate the quality of crispy biscuits prepared with soybean dregs powder.

2. Addition of soybean dregs powder in quantity above $15 \%$ made biscuits yellower and darker, and lowered the $L^{*}$.

3. Hardness and chewiness of the biscuit prepared with the addition of $10-15 \%$ of soybean powder slightly increased, which was not beneficial for biscuit making.

4. Addition of soybean dregs powder to biscuits can enhance flavor. The maximum amount of soy flour at which the organoleptic evaluation remained acceptable was $20 \%$. Additionally, further research should be conducted to study the rheological and texture properties of crispsy biscuits dough. The present research might help to enlarge the application of soybean dregs in bakeries.

\section{References}

AOAC (1995), Method 991.42 \& 993.19 official methods of analysis (16th ed.), DC: Association of Official Analytical Chemists, Washington.

Bose D., Shams-ud-Din M. (2010), The effect of chickpea (Cicer arietinim) husk on the properties of cracker biscuits, Journal of the Bangladesh Agricultural University, 8(452-2016-35753).

Bourne M. (2002), Food texture and viscosity: concept and measurement, Elsevier.

Bourquin L.D., Titgemeyer E.C., Fahey G.C., Jr. (1996), Fermentation of various dietary fiber sources by human fecal bacteria, Nutrition Research, 16(7), pp. 1119-1131.

Chen Y.J. (2013), Study on the processing technology of the suga-free okara biscuit production using bean dregs, Journal of Anhui Agricultural Sciences, pp. 2013-36. 
Chen Y., Ye R., Yin L., Zhang N. (2014), Novel blasting extrusion processing improved the physicochemical properties of soluble dietary fiber from soybean residue and in vivo evaluation, Journal of Food Engineering, 120, pp. 1-8.

Fayaz G., Plazzotta S., Calligaris S., Manzocco L., Nicoli M. C. (2019), Impact of high pressure homogenization on physical properties, extraction yield and biopolymer structure of soybean okara, LWT-Food Science and Technology, 113, 108324.

Friedman H.H., Whitney J.E., Szczesniak A. S. (1963), The texturometer - a new instrument for objective texture measurement, Journal of Food Science, 28(4), pp. 390-396.

Li B., Yang W., Nie Y., Kang F., Goff H.D. \& Cui S.W. (2019), Effect of steam explosion on dietary fiber, polysaccharide, protein and physicochemical properties of okara, Food Hydrocolloids, 94, pp. 48-56.

Li M., Zhang Y., You X., Sun J., Li Z. C., Wei P., Li L. (2015), Sensory quality evaluation and digestion properties of biscuits containing green banana powder, Food Science, $36(21), 68173$.

Mateos-Aparicio I., Mateos-Peinado C., Rup'erez P. (2010), High hydrostatic pressure improves the functionality of dietary fibre in okara by-product from soybean, Innovative Food Science \& Emerging Technologies, 11(3), pp. 445-450.

Muliterno M.M., Rodrigues D., Lima F., Ida E.I., Kurozawa L.E. (2017), Conversion/degradation of isoflavones and color alterations during the drying of okara, LWT - Food Science and Technology, 75, pp. 512-519.

O'Toole D. K., Desmond K. (1999), Characteristics and use of okara, the soybean residue from soy milk production - a review, Journal of Agricultural \& Food Chemistry, 47(2), pp. 363-371.

Pr'estamo G., Rup'erez P., Espinosa-Martos I., Villanueva M. J., Lasuncion M. A. (2007), The effects of okara on rat growth, cecal fermentation, and serum lipids, European Food Research and Technology, 225(5-6), pp. 925-928.

Qiu Y.Y., Qi Y. (2018), Production on crispy biscuit from bean dregs, Soybean Science \& Technology, pp. 39-43.

Redondo-Cuenca A., Ma V.S., Mateos-Aparicio I. (2008), Soybean seeds and its byproduct okara as sources of dietary fibre, Measurement by AOAC and Englyst methods. Food Chemistry, 108(3), pp. 1099-1105.

Rinaldi V.E.A., Ng P.K.W., Bennink M.R. (2000), Effects of extrusion on dietary fiber and isoflavone contents of wheat extrudates enriched with wet okara, Cereal Chemistry, 77(2), pp. 237-240.

Singh B., Bajaj M., Kaur A., Sharma S., Sidhu J. S. (1993), Studies on the development of high-protein biscuits from composite flours, Plant Foods for Human Nutrition, 43(2), pp. 181-189.

Stabnikova, O., Marinin, A., Stabnikov, V. (2021), Main trends in application of novel natural additives for food production, Ukrainian Food Journal, 10(3). 524-551.

Surel O., Couplet B. (2005). Influence of the dehydration process on active compounds of okara during its fractionation, Journal of the Science of Food and Agriculture, 85(8), pp. 1343-1349.

Szczesniak A.S. (1963), Classification of texture characteristics, Journal of Food Science.

Szczesniak A.S., Brandt M.A., Friedman H.H. (1963), Development of standard rating scales for mechanical parameters of texture and correlation between the objective and the sensory methods of texture evaluation, Journal of Food Science, 28(4), pp. 397-403.

Tharanathan R. N., Mahadevamma S. (2003), Grain legumes - A boon to human nutrition, Trends in Food Science \& Technology, 14(12), pp. 507-518. 
Tsubaki S., Nakauchi M., Ozaki Y., Azuma J. (2009), Microwave heating for solubilization of polysaccharide and polyphenol from soybean residue (Okara), Food Science and Technology Research, 15(3), pp. 307-314.

Tyagi S.K., Manikantan M.R., Oberoi H.S., Kaur G. (2007). Effect of mustard flour incorporation on nutritional, textural and organoleptic characteristics of biscuits. Journal of Food Engineering, 80(4), pp. 1043-1050.

Wang F., Zeng J., Gao H. Y., Sukmanov V. (2021), Effects of different physical technology on compositions and characteristics of bean dregs, Innovative Food Science and Emerging Technologies, 73, 02789.

Yan J., Chi Y. J. (2013), Effects of twin-screw extrusion on soluble dietary fibre and physicochemical properties of soybean residue, Food Chemistry, 138(2-3), pp. 884889.

Yang H., Li L., Yin Y., Li B., Zhang X., Jiao W., Liang Y. (2019), Effect of ground ginger on dough and biscuit characteristics and acrylamide content, Food Science and Biotechnology, 28(5), 1359-1366.

Yang J., Nie Y. H., Lin D. Q. (2013), Development of soybean dregs biscuit with high protein and dietary fiber, Modern Food Science \& Technology, 29(4), pp. 792-795. 